\title{
HUBUNGAN ANTARA DUKUNGAN SOSIAL DENGAN EFIKASI DIRI PADA SISWA KELAS X AKUNTANSI DI SMK BINA PANGUDI LUHUR JAKARTA
}

\author{
ANITA SARI \\ Fakultas Ekonomi, Universitas Negeri Jakarta \\ Anitasari2317@gmail.com

\section{ATI SUMIATI} \\ Fakultas Ekonomi, Universitas Negeri Jakarta \\ atisuamiati@gmai.com
}

\begin{abstract}
This research was aimed to obtain valid and reliable data about Relationship between Social Support with Self Efficacy Grade X Accounting in Vocational High School Bina Pangudi Luhur Jakarta. This research was conducted by survey method and correlational approach. Sampling technique used proportional random sampling. Affordable population in this research were Grade X Accounting students with totaling 63 students. Total of samples used were 55 students. The results showed that: there is a positive relationship between social support with self efficacy Grade $X$ Accounting in Vocational High School Bina Pangudi Luhur Jakarta. Thus if the social support increases, the self efficacy will also increase.
\end{abstract}

Key words: social support, self efficacy. 


\section{PENDAHULUAN}

Dalam keseluruhan pendidikan, kegiatan proses belajar merupakan kegiatan yang paling utama. Karena pada hakikatnya belajar merupakan kegiatan yang relatif permanen dalam perilaku atau potensi perilaku sebagai hasil dari pengalaman atau latihan yang diperkuat.

Kegiatan belajar di sekolah terutama sekolah kejuruan dituntut untuk mengembangkan keahlian sesuai jurusan yang diambil. Menurut Ginzberg dalam Mukhidin (2007) menyatakan bahwa pendidikan kejuruan adalah proses perkembangan yang bertujuan untuk meningkatkan keahlian dengan persyaratan yang ditentukan.

Untuk itu banyak praktikum dan kegiatan belajar yang harus dikerjakan oleh semua siswa, dengan banyaknya tugas-tugas belajar, baik itu tugas ketika kegiatan belajar itu berlangsung, pekerjaan rumah, ulangan harian maupun ujian. Masalah lain yang dihadapai siswa yaitu dalam menghadapi situasi sekolah, guru dan teman-teman yang berbeda karakteristiknya, untuk itu siswa harus memiliki efikasi diri yang kuat.

Efikasi diri yang dimiliki siswa dapat berpengaruh positif terhadap keberhasilan belajar yang dicapai oleh siswa, karena dengan adanya efikasi diri yang tinggi siswa mampu menyelesaikan berbagai persoalan dalam proses belajar.
Akan tetapi tidak semua siswa memiliki efikasi diri yang tinggi, hal ini dapat menghambat proses belajar dan hasil yang diraihpun juga tidak maksimal. Siswa yang memiliki efikasi yang rendah cenderung menghindari pelajaran yang banyak tugasnya, khususnya untuk tugas-tugas yang sulit, apabila memiliki permasalahan siswa tidak berani untuk menceritakan permasalahannya, siswa tidak memiliki keyakinan dalam mengerjakan soal-soal atau tugas yang diberikan oleh guru dan mudah putus asa.

Seperti kasus yang terjadi di Sekolah Menengah Atas Yayasan Sukma Bangsa, Caleue, Kecamatan Indrajaya, Pidie, NAD 11 siswa dikeluarkan dari sekolah tersebut karena kedapatan saling mencontek saat mengikuti Ujian Nasional hari kedua. Kepala SMA Sukma Bangsa Caleue, Sansrisnamenjelaskan, ke11 siswa itu kepergok mencontek saat mengikuti UN hari kedua dengan bidang studi Bahasa Inggris untuk siswa jurusan IPA dan bidang studi Ekonomi untuk jurusan IPS. (Sigie, 2012)

Dari kasus tersebut, dapat dilihat bahwa masih banyak siswa yang memiliki efikasi diri yang rendah, sehingga melakukan kecurangan dalam kegiatan belajar yaitu dengan mencontek saat kegiatan ujian berlangsung.

Efikasi diri yang rendah dipengaruhi oleh berbagai hal salah satunya dipengaruhi oleh kecerdasan emosional.Kecerdasan emosional mempunyai peran yang besar dalam menentukan 
keberhasilan dalam belajar. Namun pada kenyataannya, banyak siswa yang memiliki tingkat kecerdasan yang negatif sehingga akan berpengaruh terhadap efikasi diri.

Meningkatnya kasus tawuran pelajar di Jakarta.Sepanjang tahun 2013 ini terjadi 112 kasus dengan menewaskan 12 siswa.Arist Merdeka Sirait, Ketua Komnas Perlindungan Anak (Komnas PA) menyebutkan, tawuran pelajar tersebut bahkan sudah menjalar ke daerah. "Total kasus di seluruh Indonesia mencapai 255 kasus dengan total tewas 20 orang, terbanyak memang di Jakarta," kata Arist (Aji, 2013).

Berdasarkan kasus diatas, menunjukkan bahwa masih banyak siswa yang memiliki kecerdasan emosi yang sangat rendah, mudah terpengaruh oleh orang lain sehingga tidak bisa mengendalikan emosi, cenderung berbuat masalah disekolah maupun diluar sekolah.

Rendahnya efikasi diri siswa dalam belajar juga bisa ditentukan oleh ketidaksiapan siswa dalam belajar atau dalam menghadapi ulangan. Siswa merasa tidak yakin bisa mengerjakan semua tugastugas dan mengerjakan ulangan apabila tidak dipersiapkan sebelumnya. Seperti yang dirasakan oleh beberapa siswa Sekolah Menengah Atas (SMA) di Kota Padang mengaku masih belum maksimal dalam menghadapi yang hanya tinggal menghitung bulan ini. "Iya, persiapannya sudah sangat banyak, tapi belum begitu maksimal. Terutama dalam masalah memilah waktu yang saat ini terasa makin sedikit," Selain itu, Nurul Noveri juga merasakan hal yang sama. Dirinya mengungkapkan, meskipun sudah mengikuti bimbangan belajar untuk persiapan UN sepulang sekolah, dia mengaku masih belum bisa mengatakan sudah siap 100 persen (Liputan, 2016).

Kemudian faktor yang juga mempengaruhi efikasi diri siswa yaitu kecemasan diri, yaitu ketegangan, rasa tidak aman dan kekhawatiran yang timbul karena dirasakan terjadi sesuatu yang tidak menyenangkan. Dalam belajar ada hal yang menimbulkan kecemasan diri pada siswa seperti ujian yang akan dihadapi oleh siswa.

Menteri Pendidikan dan Kebudayaan M. Nuh mengatakan sebagian besar siswa tingkat Sekolah Menengah Atas (SMA) merasa cemas menghadapi ujian nasional.56 persen di antara mereka mengaku cemas dengan ujian nasional.Menurut Nuh, sebanyak 22,4 persen sisanya merasa sangat cemas, dan 21,6 persen tidak cemas sama sekali. (Reviyanto, 2012)

Berdasarkan data di atas, masih banyak siswa yang mengalami kecemasan sebelum menghadapi ujian. Hal ini membuat siswa merasa tidak mampu dalam menghadapi situasi yang akan terjadi. Perasaan itu akan berpengaruh pada pembentukan efikasi diri siswa.

Efikasi diri juga dapat dipengaruhi oleh dukungan sosial. Dukungan sosial adalah perasaan empati, perhatian dari orang lain yang berarti dalam kehidupan individu yang bersangkutan, dukungan tersebut bisa diperoleh 
dari keluarga atau orang tua, guru dan individu lainnya. Siswa yang tidak mendapat dukungan dari orang tua maupun guru cenderung menjadi pemalas, belajar dengan sesuka hati, menghindari pekerjaan yang sulit dan memiliki efikasi diri yang rendah. Seperti yang terjadi dalam pelaksanaan UN SMP dan MTS ada 39 siswa yang berhalangan mengikuti UN sampai hari kedua pelaksanaan UN. Data yang kami peroleh, 13 siswa tidak hadir lantaran dalam kondisi sakit, kemudian 3 siswa lainnya izin dan 23 siswa diketahui telah mengundurkan diri (Kuningan, 2014).

Berbeda lagi dengan hasil pengamatan langsung yang peneliti lakukan di salah satu SMK Swasta di Jakarta yaitu SMK Bina Pangudi Luhur, peneliti menemukan beberapa siswa yang mempunyai masalah yang berhubungan dengan efikasi diri siswa, yaitu masih ada siswa yang tidak masuk sekolah tanpa keterangan, tidak mengerjakan tugas dan masih banyak siswa yang mencontek ketika ulangan dan disebabkan karena beberapa faktor salah satunya yaitu dukungan sosial.Siswa cenderung untuk bergantung pada kemampuan orang lain karena tidak yakin pada kemampuan yang dimilikinya sendiri. Hal ini peneliti ketahui dari hasil wawancara dengan guru.

\section{Perumusan Masalah}

Berdasarkan pemaparan yang telah dilakukan di atas,maka perumusan masalah dalam penelitian sebagai berikut: "apakah terdapat hubungan antara dukungan sosial terhadap efikasi diri siswa dalam belajar?"

\section{KAJIAN PUSTAKA Efikasi Diri}

Menurut Greenberg dan Baron (Baron, 2008) "Self efficacy is one's belief about having the capacity to perform a task."Dapat diartikan efikasi diri adalah seseorang yang memiliki keyakinan tentang kemampuan untuk melakukan tugas.

Schermerhorn,et.al.,(Schermerh orn, 2011) mengemukakan bahwa "Self efficacy is a person's belief that she or he is capable of performing a task'Efikasi diri adalah keyakinan seseorang bahwa dia mampu melakukan tugas.

Erica Frydenberg (Frydenberg, 2004) "self efficacy comprises the belief in one's ability to perform specific task"Dapat diartikan efikasi diri terdiri dari keyakinan dalam kemampuan seseorang untuk melakukan tugas tertentu.

Berdasarkan pengertian diatas dapat disimpulkan bahwa efikasi diri adalah keyakinan atau kepercayaan seseorang pada kemampuan yang dimilikinya untuk mengerjakan tugas.

Sementara menurut Miller \& Rollnick "Self-efficacy as a person's belief in his or her ability to carry out and succeed with a specific task'yang artinya efikasi diri sebagai keyakinan seseorang pada kemampuannya untuk 
melaksanakan dan berhasil dengan tugas tertentu.

Kreitner dan Kinicki (Kreitner, 2008) " Self efficacy is a person belief about his or her chances of successfully accomplishing a specific task" dapat diartikan efikasi diri adalah keyakinan seseorang tentang kemampuannya menyelesaikan tugas tertentu dengan sukses.

McShane dan Von Glinow (Lattimore McShane, 2010) "Self efficacy refers to a person belief that he or shecan successfully complete task" yang artinya keyakinan seseorang bahwa ia dapat berhasil dalam menyelesaikan tugas.

Dari pengertian di atas dapat disimpulkan bahwa efikasi diri adalah keyakinan seseorang bahwa ia memiliki kemampuan untuk menyelesaikan tugas dengan berhasil. Hal ini bertujuan agar siswa dapat menjalankan aktivitas belajar dengan baik karena memiliki keyakinan diri yang kuat dalam mengerjakan semua tugas-tugas dalam belajar sehingga dapat mencapai tujuan belajar dengan baik dan berhasil sesuai yang diharapkan

Menurut Simon dan Michael (Priest, 2005) efikasi diri (self efficacy) yang dimiliki seseorang mengacu pada tiga dimensi yaitu :

(1)Magnitude, refers to the degree of certainty associated with success and is heavily influenced by perceptions of risk and difficulty. Magnitude, mengacu pada derajat kepastian yang terkait dengan keberhasilan dan sangat dipengaruhi oleh persepsi risiko dan kesulitan. (2) Strength, refers to how long a person holds on to expectations of success despite contradictory information. Kekuatan, mengacu pada berapa lama seseorang berpegang pada harapan keberhasilan meskipun informasi yang kontradiktif. (3) Generality, refers to the degree of transfer of self-efficacy beliefs from one situation to another.Secara umum, mengacu pada tingkat transfer keyakinan self-efficacy dari satu situasi ke yang lain.

Menurut Elizabeth et.al (Elizabeth, 2002)Konsep dari efikasi diri mencakup tiga dimensi yaitu "Magnitude, refers to how difficult a person finds it to adopt a specific behavior. Strength reflects how certain a person is of being able to perform a specific task. Generality refers to the degree to which selfefficacy beliefs are positively related, either within a behavioral domain, across behavioral domains or across time."Artinya Magnitude, mengacu pada bagaimana sulitnya seseorang menemukan itu untuk mengadopsi perilaku tertentu. Strength mencerminkan bagaimana seseorang untuk dapat melakukan tugas tertentu.Generality mengacu pada sejauh mana keyakinan selfefficacy berhubungan positif, baik dalam domain perilaku, seluruh domain perilaku atau di waktu.

Sedangkan menurut $M$. Nur Ghufron dan Rini Risnawita S (Ghufron, 2010) tiga dimensi efikasi diri adalah (a) Dimensi tingkat level (magnitude), dimensi ini berkaitan dengan derajat kesulitan tugas 
ketika individu merasa mampu untuk melakukannya. Individu akan mencoba tingkah laku yang dirasa mampu dilakukannya dan menghindari tingkah laku yang berada di luar batas kemampuan yang dirasakannya. (b) Dimensi kekuatan (strength), dimensi ini berkaitan dengan tingkat kekuatan dari keyakinan atau pengharapan individu mengenai kemampuannya. Pengharapan lemah mudah digoyahkan oleh pengalaman yang tidak mendukung, sebaliknya pengharapan yang mantap mendorong individu untuk tetap bertahan dalam usahanya. (c) Dimensi generalisasi (generality), dimensi ini berkaitan dengan luas bidang tingkah laku, yang mana individu merasa yakin akan kemampuannya. Individu dapat merasa yakin terhadap kemampuan dirinya. Apakah terbatas pada suatu aktivitas atau situasi tertentu atau pada serangkaian aktivitas dan situasi yang bervariasi.

Jadi dapat disimpulkan bahwa efikasi diri adalah keyakinan atau kepercayaan seseorang pada kemampuan yang dimilikinya untuk mengerjakan tugas dengan baik dan berhasil. Efikasi itu mempunyai 3 dimensi yang terdiri dari magnitude, strength dan generality. Magnitude yaitu tentang keyakinan yang dimiliki seseorang untuk menyelesaikan tugas pada tingkat kesulitan tertentu, Strength yaitu tingkat kekuatan dari keyakinan individu sejauh mana keyakinan untuk bertahan dalam menyelesaikan tugas, Generalitymampu mengatasi situasi tertentu atau situasi yang bervariasi, mengacu pada tingkat transfer keyakinan self-efficacy dari satu situasi ke yang lain.

\section{Dukungan Sosial}

V.K. Kool (Agrawal, 2006) "social support can be defined as the comfort, assistance, or information one receives through formal and informal contacts with individual or group" Yang diartikan, dukungan sosial didefinisikan sebagai kenyamanan, bantuan, atau informasi yang diterimanya melalui kontak formal dan informal dengan individu atau kelompok.

Longres

(2004:101)

mendefinisikan "social support social support as the comfort, assistance or information individuals receive through their formal or in formal with others, based on the principles of mutual aid'yang artinya dukungan social sebagai kenyamanan, bantuan, atau individu menerima informasi melalui formal atau informal dengan orang lain, berdasarkan prinsip-prinsip saling membantu.

Selanjutnya menurut Wallston dalam Jane Ogden (Ogden J. , 2007) "the term 'social support' is generally used to refer to the preceived confort, caring, esteem or help one individual receives from other". Diartikan bahwa, istilah 'dukungan sosial' umumnya digunakan untuk merujuk pada kenyamanan yang dirasakan, kepedulian, penghargaan atau bantuan yang diterima individu dari orang lain. Sehingga seorang 
individu merasa diterima dimana ia berada.

Berdasarkan pengertian di atas, dapat disimpulkan bahwa dukungan sosial merupakan kenyamanan, bantuan, kepedulian maupun penghargaan yang diterima oleh individu atau kelompok.

Dukungan sosial sangat penting bagi individu, seperti yang diungkapkan oleh Laura A. King (A.King, 2010) social supportadalah informasi umpan balik dari orang lain yang menunjukan bahwa seseorang dicintai dan diperhatikan, dihargai, dan dihormati, dan dilibatkan dalam jaringan komunikasi dan kewajiban yang timbal balik.

Siegel (2003:315) menyatakan bahwa "Social support has been defined as information from others that one is loved and cared for, esteemed and valued, and part of a network of communication and mutual obligation" Maksudnya dukungan sosial dapat diartikan sebagai informasi dari orang lain yang menunjukkan bahwa ia di cintai dan diperhatikan, memiliki harga diri dan dihargai, serta merupakan bagian dari jaringan komunikasi dan kewajiban bersama.

Kemudian Haber's (2003) mengatakan bahwa "social support refers to this subjectivity, the perceived caring, esteem, and assistance people receive from other'yang didefinisikan dukungan sosial mengacu pada subjektivitas, dianggap peduli, dihargai, dan bantuan yang menerima dari orang lain.

Cohen \& McKey dalam Sheldon et, al., (Sheldon Cohen et, 2000) membagi dukungan sosial ke dalam lima bentuk, yaitu: (1) Dukungan emosi, bentuk dukungan yang diekspresikan melalui perasaan positif seperti empati, perhatian, kepedulian, perasaan nyaman, perasaan dilibatkan, dan dicintai oleh individu yang bersangkutan. (2) Dukungan penghargaan, bentuk dukungan melalui ungkapan, penghargaan atau penilaian yang positif untuk individu, dorongan, dan pemberian semangat. (3) Dukungan instrumental, bentuk dukungan yang dapat diwujudkan dalam bentuk bantuan langSung misalnya pemberian dana atau pemberian bantuan tindakan nyata atau benda. (4) Dukungan informasi, dapat diungkapkan dalam bentuk pemberian nasehat atau saran, pengarahan, dan umpan balik. (5) Dukungan jaringan sosial, menggambarkan hubungan persahabatan yang memungkinkan individu melakukan aktivitas sosial

Berbeda dengan pendapat yang dikemukakan menurut Nursalam mengenai bentuk-bentuk dukungan sosial (Dian Kurniawati, 2007), Nursalam membagi dukungan sosial menjadi: (1) Dukungan emosional, mencakup empati, kepedulian, dan perhatian terhadap orang yang bersangkutan (2) Dukungan penghargaan, terjadi lewat ungkapan hormat/ penghargaan positif untuk orang lain itu, 
dorongan maju atau persetujuan dengan gagasan atau perasaan individu, dan perbandingan positif orang itu dengan orang lain, misalnya orang itu kurang mampu atau lebih buruk keadaannya (menambah harga diri). (3) Dukungan informatif, mencakup pemberian nasihat, saran, pengetahuan, dan informasi serta petunjuk.

Sedangkan Lynda (Juall Carpenito, 2009) membagi dukungan sosial menjadi empat dasar jenis dukungan sosial: (1) Emosional (perhatian dan kepercayaan) (2) Penilaian (memperkuat harga diri) (3) Informasi (nasihat yang bermanfaat, informasi untuk memecahkan masalah) (4) Instrumental ( Pemberian asuhan) atau bantuan nyata (uang, atau bantuan pada pekerjaan rumah)

Dari bentuk-bentuk dukungan sosial tersebut maka dapat ditarik kesimpulan bahwa dukungan yang diperlukan dan diterima individu tergantung pada keadaan dan situasi yang dialami. Ada lima bentukdukungan sosial yaitu dukungan instrumental, dukungan emosional, dukungan penghargaan, dukungan informasi, dan dukungan jaringan sosial. Maka bentuk dukungan sosial yang dibutuhkan dalam efikasi diri individu dalam kehidupannya adalah dukungan emosional, dukungan instrumental, dukungan informasi dan dukungan penghargaan.Dukungan emosional seperti memberikan empati, perhatian, kepedulian, perasaan nyaman, dilibatkan, dan dicintai oleh individu bersangkutan.Dukungan instrumental seperti bantuan terhadap masalah, bantuan dana dan barang. Dukungan informasi mencakup pemberian nasihat, saran dan informasi. Dukungan penghargaan memberikan dorongan atau menambah harga diri.

David French, dkk (al, 2010)mengatakan bahwa, "social support received from foursources, namely freinds, family, spouses and group/organizations".Yang diartikan, dukungan sosial diterima dari empat sumber, yaitu teman-teman, keluarga, pasangan dan kelompok/organisasi.

Kemudian Jerrold S. Greenberg (S.Greenberg,2002)

mengungkapkan bahwa, "social support can be provided by family members, friends, lovers, or anyone else". Diartikan bahwa, dukungan sosial dapat diperoleh dari anggota keluarga, teman, kekasih, atau orang lain.

Selanjutnya menurut Wallston, Will and Fegan dalam Edward P. Sarafino (Sarafino, 2007), "Social support refers to the perceived comfort, caring, esteem, or help a person receives from other people or groups. This support can come from many different sources the person's spouse or lover, family, friends, coworkers, physicians, or community organizations".Yang dapat diartikan, "dukungan sosial mengacu pada kenyamanan yang dirasakan, kepedulian, 
penghargaan, atau bantuan yang diterima seseorang dari orang lain atau kelompok. Dukungan ini dapat berasal dari berbagai sumber seperti pasangan atau kekasih, keluarga, teman, rekan kerja, dokter, atau organisasi masyarakat.

Dari definisi diatas dapat
disimpulkan bahwa, sumber
dukungan sosial dapat diperoleh
dari anggota keluarga misalkan
orang tua, teman dan orang lain.
Dukungan tersebut bisa berupa
perhatian, kepedulian, bantuan
uang dan lain sebagainya.
Dukungan ini sangat penting bagi
setiap individu karena dengan
adanya dukungan sosial individu
merasa dihargai dicintai dan
diperhatikan.

Efikasi diri yang terdapat dalam siswa dipengaruhi oleh dukungan sosial. Dukungan sosial bisa diperoleh dari guru, keluarga atau orang tua maupun dari teman.

Menurut Duncan and McAuley (2002) "Have found that social support influences exercise behaviors indirectly by improving one's self-efficacy" Telah menemukan bahwa dukungan sosial mempengaruhi perilaku latihan secara tidak langsung dengan meningkatkan efikasi diri seseorang.

Kemudian Sarason, and Pierce (1997) mengatakan "Report that social support is related to greater self-efficacy, more effective stress management, and reduced anxiety.Melaporkan bahwa dukungan sosial berhubungan dengan efikasi diri yang lebih besar, manajemen stress lebih efektif, dan mengurangi kecemasan.

Sedangkan menurut Major (2006) "Social support may enhance change because it contributes to self efficacy'Dukungan sosial dapat meningkatkan perubahan karena memberikan kontribusi terhadap efikasi diri.

Pendapat Uichol Kim et, al. (2006) "Social support received from significant others help to raises the self-efficacy beliefs for children and adolescents"Jika diartikan, dukungan social yang diterima dari orang lain yang signifikan membantu meningkatkan keyakinan efikasi diri untuk anak-anak dan remaja.

\section{METODE PENELITIAN}

Tujuan penelitian ini adalah untuk mengetahui hubungan antara dukungan sosial dengan efikasi diri pada siswa di SMK Bina Pangudi Luhur Jakarta berdasarkan data atau fakta yang tepat (sahih, benar dan valid) dan dapat dipercaya (diandalkan, reliabel).

Metode yang digunakan dalam penelitian ini adalah metode survey dengan pendekatan korelasional.

Populasi dalam penelitian ini adalah seluruh siswa SMK BinaPangudiLuhurJakarta Tahun Ajar 2014-2015.Sedangkan populasi terjangkau dalam penelitian ini adalah siswa kelas $X$ Akuntansi yang berjumlah 63 siswa yakni $X$ Akuntansi 1 yang berjumlah 32 siswa dan $X$ akuntansi 2 yang berjumlah 31 siswa. Kemudian berdasarkan tabel Isaac dan Michael 
dengan taraf kesalahan 5\%, maka jumlah sampel sebanyak 55 siswa.

Sebelum dilakukan pengujian hipotesis, terlebih dahulu dilakukan pengujian persyarat ananalisis, meliputi Uji Normalitas dan Uji Linearitas Regresi.

Teknik yang digunakan untuk melakuka npengujian normalitas data adalah UjiLiliefors. Data yang terkumpul kemudian dianalisis dengan regresi dankorelasi.

\section{HASIL DAN PEMBAHASAN}

Berikut adalah distribusi data hasil penelitian.

Tabel 1.Rangkuman Deskripsi Data

\begin{tabular}{|l|c|c|}
\hline $\begin{array}{c}\text { Nilai } \\
\text { Tendensi } \\
\text { Sentral }\end{array}$ & $\begin{array}{c}\text { Dukungan } \\
\text { Sosial }(\mathrm{X})\end{array}$ & $\begin{array}{c}\text { Efikasi Diri } \\
(\mathrm{Y})\end{array}$ \\
\hline $\mathrm{N}$ & 55 & 55 \\
\hline Mean & 89.35 & 115.80 \\
\hline Std. Deviasi & 8.24 & 10.24 \\
\hline Varians & 67.90 & 104.76 \\
\hline
\end{tabular}

\section{Uji Persyaratan Analisis}

\section{Uji Normalitas}

Pengujian normalitas yang digunakan adalah Uji Liliefors. Hasil Uji Normalitas terdapat pada tabel 2 berikut:

Tabel 2.Rangkuman Hasil Uji Normalitas

\begin{tabular}{|c|c|c|c|c|}
\hline $\begin{array}{c}\text { Galat } \\
\text { Taksiran } \\
\text { Regresi }\end{array}$ & $\mathrm{n}$ & Lhitung & $\begin{array}{c}\text { Ltabel } \\
\alpha= \\
5 \%\end{array}$ & Keterangan \\
\hline Y atas X & 55 & 0,0504 & 0,119 & Normal \\
\hline
\end{tabular}

Uji Linearitas Regresi
Bentuk persamaan regresi berbentuk linear. Hal ini dapat dibuktikan dengan hasil penghitungan. $\quad F_{\text {hitung }}=0,86$; sedangkan $\mathrm{F}_{\text {tabel }}=2.00$.

\section{Pengujian Hipotesis}

Hasil analisis data menginformasikan bahwa persamaan regresi pasangan variabel ini adalah $\hat{Y}=50.62+$ $0,730 \mathrm{x}$.

Hal ini dapat dibuktikan dengan hasil perhitungan Fhitung yang diperoleh sebesar 27,94 sedangkan taraf signifikan (a) $=0,05$ dengan derajat kebebasan (dk) pembilang bernilai 1 dan derajat kebebasan (dk) penyebut bernilai 53, diperoleh Ftabelsebesar 4,03. Hal ini berarti bahwa Ho ditolak karena Fhitung< Ftabel yang berarti persamaan regresi yang diperoleh adalah berarti atau signifikan.

Selanjutnya, tingkat hubungan antarvariabel dihitung melalui korelasi Product moment, kemudian koefisien determinasi.

Hasil pengujian hipotesis, diperoleh data yang menunjukkan terdapat hubungan yang positif antara dukungan sosial dengan efikasi diri pada siswa kelas $X$ Jurusan Akuntansi SMK Bina Pangudi Luhur Jakarta.Koefisien korelasi yang diperoleh yaitu sebesar 0,587. Keberartian koefisien korelasi menghasilkan thitung sebesar 5,28 dan trabelsebesar 1,68 maka terdapat hubungan yang signifikan antara kedua variabel.

Besarnya hubungan variabel dukungan sosial dengan efikasi diri pada siswa dapat diketahui dengan melihat hasil perhitungan uji 
koefisien determinasi sebesar $34,50 \%$ yang berarti bahwa tingkat efikasi diri pada siswa $34,50 \%$ variasi perubahan efikasi diri pada siswa kelas $X$ Jurusan Akuntansi SMK Bina Pangudi Luhur Jakarta ditentukan oleh dukungan sosial.

\section{KESIMPULAN, IMPLIKASI, DAN SARAN}

\section{Kesimpulan}

Terdapat hubungan positif dan signifikan antara kedua variabel yakni dukungan sosial (variabel $X$ ) dan efikasi diri (variabel $Y$ ).Besaran hubungan dukungan sosial dan efikasi diri yaitu sebesar 34.50\%.

\section{Implikasi}

Implikasi dari hasil penelitian ini adalah siswa harus diberikan dukungan sosial yang penuh dari guru. Dukungan sosial yang diberikan adalah dukungan informasi yaitu berupa nasehat, saran dan informasi. Guru yang memberikan dukungan informasi berupa nasehat, saran dan informasi atau petunjuk kepada siswa cenderung membuat siswa lebih percaya diri dan yakin akan kemampuannya untuk mengerjakan semua tugas-tugas akademik yang diberikan oleh guru.

\section{Saran}

Berdasarkan kesimpulan dan implikasi yang dikemukakan diatas, saran yang dapat diberikan oleh peneliti yaitu:

1. Untuk siswa, diharapkan memiliki efikasi diri yang tinggi dalam belajar, agar dapat mempertahankan keyakinan akan kemampuannya dalam mengerjakan setiap tugas akademik yang diberikan oleh guru dalam belajar.

2. Kepada guru atau tenaga pengajar untuk dapat lebih memperhatikan lagi perilaku belajar siswa. Guru sebaiknya memberikan dukungan sosial baik berupa kepedulian, penghargaan, bantuan, nasehat, informasi, kenyamanan yang penuh kepada siswa agar dapat mengakibatkan efikasi diri yang tinggi pada siswa.

3. Untuk peneliti selanjutnya, diharapkan mengembangkan penelitian ini dengan cakupan populasi yang lebih luas dengan tempat yang berbeda sehingga didapatkan karakteristik siswa yang berbeda dari penelitian iniataupun dengan menambah variabel lain yaitu hasil belajar.

4. Untuk Sekolah, agar lebih memperhatikan dan mengontrol prilaku siswa dalam belajar dengan memberikan dukungan yang memicu siswa untuk belajar mandiri dan mengerjakan tugas-tugas belajarnnya dengan kemampuannya sendiri.

\section{DAFTAR PUSTAKA}

A.King, L. (2010). Psikologi Umum Sebuah Pandangan Apresiatif. Jakarta: Salemba.

Agrawal, .. K. (2006). Applied Social Psychology A Global Perspective. New Delhi: Atlantic Publishers. 
Aji, W. (2013). kasus tawuran pelajar jakarta terus meningkat tahun ini. Jakarta: http://www.tribunnews.com/ metropolitan/2013/12/22/kas us-tawuran-pelajar-jakartaterus-meningkat-tahun-ini.

al, D. F. (2010). Helath Psychology. Oxford: :The British Psychology Society.

Baron, G. d. (2008). Behavior inOrganizationgth edition. New Jersey : Prentice Hall.

Dian Kurniawati, N. d. (2007). Asuhan Keperawatan pada Pasien Terinveksi HIV/AIDS. Jakarta : Salemba Medika.

Elizabeth, e. a. (2002). Self-Efficacy In Nursing: Research and Measurement Perspectives. New York: Springer Publishing Company.

Frydenberg, E. (2004). Thriving, Surviving, Or Going Under: Coping with Everyday Live. Australia: IAP.

Ghufron, M. N. (2010). Teori-teori Psikologi. Yogyakarta: Ar-Ruzz Media. Yogyakarta: Ar-Ruzz Media.

http://pikiranmerdeka.com. (2012). mencontek-saat-un-11-siswasukma-bangsa-dikeluarkan. http://pikiranmerdeka.com.

http://pikiranmerdeka.com/read/928 /2012/04/19/. (2012). mencontek-saat-un-11-siswa- sukma-bangsa-dikeluarkan. http://pikiranmerdeka.com.

Juall Carpenito, L. (2009). DiagnosisKeperawatan: Aplikasi Pada Praktik Klinis Ed.9 Terjemahan Kusrini Semarwati, dkk. Jakarta: EGC.

Kreitner, R. d. (2008). Organizational Behavior 5th edition. New York: McGrawHill,.

Kuningan. (2014). dedi: minimnya dukungan orang tua. http://www.radarcirebon.com /dedi-minimnya-dukunganorang-tua.html.

Lattimore McShane, S. d. (2010). Organizational Behavior 5th edition. New York: McGrawHill.

Liputan. (2016). un semakin dekat pelajar harap-harap cemas. Padang: http://kabarpadang.com/unsemakin-dekat-pelajar-harapharap-cemas/ .

Ogden, J. (2007). Health Psychology $A$ Textbook 4th edition. New York: McGraw- Hill.

Ogden, J. H.-H. (2007). Health Psychology A Textbook 4th edition. New York: McGrawHill.

Priest, S. d. (2005). Effective Leadership in Adventure Programming. USA: Human Kinetics. 
Reviyanto, D. (2012). 56 Persen Siswa SMA Cemas Hadapi Ujian Nasional. Jakarta: http://www.tempo.co/read/n ews/2012/04/20/079398556/ 56-Persen-Siswa-SMA-CemasHadapi-Ujian-Nasional.

S. Greenberg, J. (2002). Comperhensive Stress Management 8th edition. New York: McGraw Hill.

Sarafino, E. P. (2007). Health Psychology 6th edition. USA: Jhon Wiley \& Sons.

Schermerhorn, e. a. (2011). Organizational Behavior 7th edition. USA: John Wiley \&Sons(Asia.

Sheldon Cohen et, a. (2000). Social Support Measurement and Intervention : $A$ Guide for Health and Social Scientists. New York: Oxford University Pers.

Sigie. (2012). mencontek-saat-un11-siswa-sukma-bangsa-

dikeluarkan. pidie: http://pikiranmerdeka.com/re ad/928/2012/04/19/mencont ek-saat-un-11-siswa-sukmabangsa-dikeluarkan. 